\title{
Optimized design and field experiment of a staggered vibrating subsoiler for conservation tillage
}

\author{
Yunxia Wang ${ }^{1}$, Abdalla N Osman ${ }^{2}$, Dongxing Zhang ${ }^{1 *}$, Li Yang ${ }^{1}$, Tao Cui ${ }^{1}$, Xiangjun Zhong ${ }^{1}$ \\ (1. College of Engineering, China Agricultural University, Beijing 100083, China; \\ 2. Department of Agricultural Machinery, College of Agricultural Studies, Sudan University of Science and Technology, Khartoum, Sudan)
}

\begin{abstract}
Soil compaction is a common problem facing conservation fields that restricts crop root growth and causes yield decrease. Subsoil techniques have been developed to break up the compaction layer. However, subsoil implement requires large draft power that hampered the development of subsoil techniques for most of developing countries due to lack of large scale tractors. Aiming to optimize the penetration resistance of the subsoiler and create a good working environment for the operators, a staggered vibrating subsoiler was developed. A new staggered vibrating mechanism was designed to generate the staggered vibration of the shanks meanwhile the V-shape shanks arrangement was adopted to keep relative balance for the subsoiler. In order to obtain optimum working parameters of the vibration frequency and forward speed, the trajectory of shanks was simulated by using the MATLAB software. The forward speed of $2-3 \mathrm{~km} / \mathrm{h}$ with vibration frequency of $12 \mathrm{~Hz}$ was recommended to acquire an effective decrease in draft force. Field performance of this subsoiler was evaluated in terms of the draft force, power requirement and tractor wheel slippage. By comparing the two operation modes, staggered vibrating $(\mathrm{SV})$ and rigid (NV) of shanks, the decrease ratios of draft force for SV were determined by $16.97 \%, 12.12 \%$ and $9.02 \%$ at forward speeds of $2.2 \mathrm{~km} / \mathrm{h}, 2.6 \mathrm{~km} / \mathrm{h}$ and $3.1 \mathrm{~km} / \mathrm{h}$, respectively. This is better than the research for the $1 \mathrm{SZ}-460$ vibratory subsoiler that was decreased by $9.09 \%$ in draft force. The power requirement for SV was not significantly greater than that for NV. The obviously decreased wheel slippage was observed for SV by decrease of $12.47 \%, 17.96 \%$ and $21.79 \%$ at forward speeds of $2.2 \mathrm{~km} / \mathrm{h}, 2.6 \mathrm{~km} / \mathrm{h}$ and $3.1 \mathrm{~km} / \mathrm{h}$, respectively. In conclusion, the staggered vibrating subsoiler presents preferable working performance and is recommended to be applied in subsoil tillage process for developing countries.
\end{abstract}

Keywords: vibrating subsoiler, staggered vibrating mechanism, V-shape arrangement, field experiment DOI: $10.25165 / \mathrm{j}$.ijabe.20191201.4297

Citation: Wang Y X, Osman A N, Zhang D X, Yang L, Cui T, Zhong X J. Optimized design and field experiment of a staggered vibrating subsoiler for conservation tillage. Int J Agric \& Biol Eng, 2019; 12(1): 59-65.

\section{Introduction}

Tillage is a basic practice in the crop production ${ }^{[1]}$. It is a process of mechanical manipulation of the soil by changing soil physical properties such as soil bulk density, soil moisture content and soil aggregate size. The main aims of the proper tillage are to provide a suitable environment for seed germination, root growth, and weed control ${ }^{[2-4]}$.

Soil compaction is one of the major problems facing conservation field $^{[5,6]}$. The majority of soil compaction in modern agriculture is due to the traffic of tractors during cultivation and harvesting $^{[7,8]}$. A wide range of subsoil implements are used for the purpose of loosening, fissuring and rearranging compaction

\section{Received date: 2018-04-04 Accepted date: 2018-12-12}

Biographies: Yunxia Wang, $\mathrm{PhD}$, research interests: conservation tillage and tropical agricultural machinery, Email: wangyxsdau@126.com; Abdalla N Osman, Associate Professor, research interests: agricultural machinery equipment and computer control technique, Email: ginan99@163.com; Li Yang, Professor, research interests: agricultural machinery equipment and computer control technique, Email: yangli@cau.edu.cn; Tao Cui, Associate Professor, research interests: agricultural machinery equipment and computer control technique, Email: cuitao850919@163.com; Xiangjun Zhong, PhD, research interests: conservation tillage and tropical agricultural machinery, Email: xjzhong1004@163.com.

*Corresponding author: Dongxing Zhang, Professor, research interests: agricultural machinery equipment and computer control technique. College of Engineering, China Agricultural University, 17 Qinghua East Road, Beijing 100083, China. Email: zhangdx@cau.edu.cn. layer. The implements which were used for this purpose include ploughs and subsoilers ${ }^{[9,10]}$.

Subsoiling will not overturn the top soil but disturb the compaction layer, which result in improving the permeability of soil, increasing the efficiency of rainwater use, and improving the ability of water conservation in arid areas ${ }^{[11,12]}$. Subsequently, subsoiling can minimize the effect of drought and lead to an increase in crop yield ${ }^{[13,14]}$.

It has been an important issue on subsoil implement to reduce the draft force, especially for developing countries because of the lack of large power tractors ${ }^{[15]}$. But reduced draft force is not easily available. Yow and Smith $^{[16]}$ studied that reduced draft force could be achieved by the use of vibrating mechanism when the maximum velocity of vibration was greater than the forward velocity of the tool. Zhang et al. ${ }^{[15]}$ developed a bionic vibrating subsoiler for banana fields. Draft force decreased approximately by $14 \%$ but fuel consumption increased by $22 \%$. Guillen-Sánchez et al. ${ }^{[17]}$ found a reduction of the draft force up to $50 \%$ using the vibrating tillage compared to the rigid tine. Shahgoli et al. ${ }^{[18]}$ developed vibrating ripper and demonstrated that $-22.5^{\circ}$ oscillation angle was the optimum for draft force reduction and power saving.

Over the above mentioned vibrating subsoilers, it is found that the tines arranged in one row and vibrating synchronously are commonly adopted. This type of subsoiler may face high soil penetration resistance because all tines will penetrate the hard soil at the same time. Moreover, most common of vibrating subsoiler 
when they tested in the field indicated that the tractor vibrations were not comfortable to the operator ${ }^{[19]}$.

It is assumed that a staggered vibrating mechanism would acquire more decrease in draft force because only half of shanks penetrate the no-tilled soil at once. Additionally, a V-shape of the shanks arrangement rather than one row would be favor for keeping balance for vibrating subsoiler.

Therefore, the general purposes of this study is to optimize the penetration resistance and keep the vibration balance for the subsoiler during its work on the field thus to reduce more draft force and create a good working environment for the operators. The specific objectives are to (1) develop staggered vibrating subsoiler with staggered vibrating mechanism, (2) analysis the trajectory of shanks arranged at V-shape based on MATLAB to obtain the optimum working parameters, (3) evaluate the field performance of the subsoiler in terms of the draft force, power requirement and tractor wheel slippage.

\section{Machine description}

\subsection{Component of the subsoiler and its working principle}

The new staggered vibrating subsoiler mainly consists of five parts, as shown in Figure 1. The three-point suspension is located the front of the machine to connect it with a tractor. The two reciprocating motion units are symmetrically mounted on the main frame in the horizontal direction. There are four subsoil shanks and every two shanks are installed on the right or left reciprocating motion unit with the V-shape arrangement. The depth control mechanism is mounted on the main frame on each side. The parameters of this subsoiler are shown in Table 1.

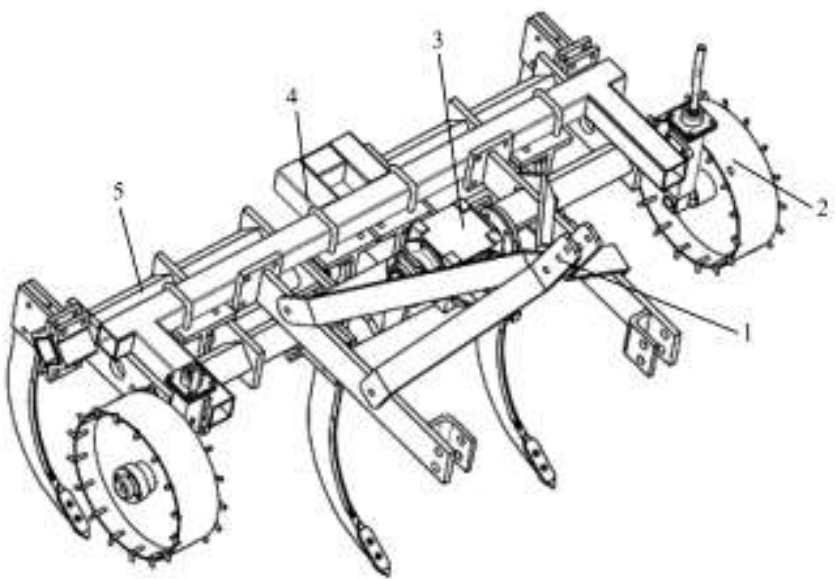

$\begin{array}{lll}\text { 1. Three-point suspension } & \text { 2. Depth control mechanism } \quad 3 \text {. Staggered vibrating }\end{array}$ mechanism 4. Main frame 5. Reciprocating motion unit

Figure 1 Component of the staggered vibrating subsoiler

Table 1 Working parameters of the staggered vibrating subsoiler

\begin{tabular}{lc}
\hline \multicolumn{1}{c}{ Parameters } & Value \\
\hline Dimensions $(\mathrm{L} / \mathrm{W} / \mathrm{H}) / \mathrm{mm}$ & $1400 / 2400 / 1270$ \\
Weight $/ \mathrm{kg}$ & 250 \\
Power/kW & $80-100$ \\
Working rows & 4 \\
Working row space $/ \mathrm{mm}$ & 600 \\
Working depth/cm & $25-40$ \\
Penetration angle of shank $/\left(^{\circ}\right)$ & 25 \\
\hline
\end{tabular}

When the subsoiler is on operation, the power take-off (PTO) shaft of the tractor is connected to the staggered vibrating mechanism. The rotation of the PTO shaft is transformed to the staggered flapping of the vibration mechanism, which leads to the reciprocating motion units moving up and down. The shanks mounted on the two reciprocating motion units penetrate into the untilled soil in turns. The subsoil depth could be adjusted by the depth control mechanism.

\subsection{Staggered vibrating mechanism}

The new staggered vibrating mechanism is the key to cause the staggered vibration for the shanks. The staggered vibration is expected to reduce more draft force by making only half shanks penetrate the untilled soil at the same time.

Figure 2 shows the structure of the staggered vibrating mechanism that is mainly composed of a gear box (one input shaft and two output shafts), two eccentric cranks, two connecting rods and two vibrating arms. The gear box was mounted on the center of the frame. The two eccentric cranks are respectively fixed on the two output shafts of the gear box. Each of eccentric cranks is connected to the vertical connecting rod; each of the vertical connecting rod is connected to a horizontal vibrating arm. The connection between of the eccentric crank and connecting rod, the connecting rod and the vibrating arm are not fixed, so that the angle between the connecting rod and the vibrating arm can change and the connecting rod move up and down as the eccentric crank rotates around. The other end of the vibrating arm is fixed on the reciprocating motion unit therefore it will move up and down together.



$\begin{array}{llll}\text { 1. Eccentric crank } & \text { 2. Connecting rod } & 3 \text {. Vibrating arm } & \text { 4. Left reciprocating }\end{array}$ motion unit 5 . Right reciprocating motion unit

Figure 2 Component of the staggered vibrating mechanism

The staggered vibration of the shanks is achieved by adjusting the two eccentric cranks at a phase difference of $180^{\circ}$. Figure 3 shows the displacement of the two eccentric cranks when it rotates in a clockwise direction. As it rotates clockwise, it leads to pushes down and up on the connecting rod, which in turn, causes the vibrating arm to move up and down. When the right connecting rod moves to the top point in the vertical direction, the left connecting rod would move to the bottom point. Similarly, when the right connecting rod moves to the forward point in the horizontal direction, the left connecting rod would move to the backward point in the opposite direction, which causes a staggered vibrating for the two vibrating arms and then drive the two reciprocating motion units with a semi-circular movement. Consequently the two shanks on the right reciprocating motion unit and the other two shanks on the left reciprocating motion unit vibrate staggeringly.

\subsection{V-shape arrangement of shanks}

The V-shape arrangement of shanks aims to keep the balance for the subsoiler and create a comfortable working environment for the operator by avoiding the machine resonance generally caused by the synchronized motion of all shanks. 


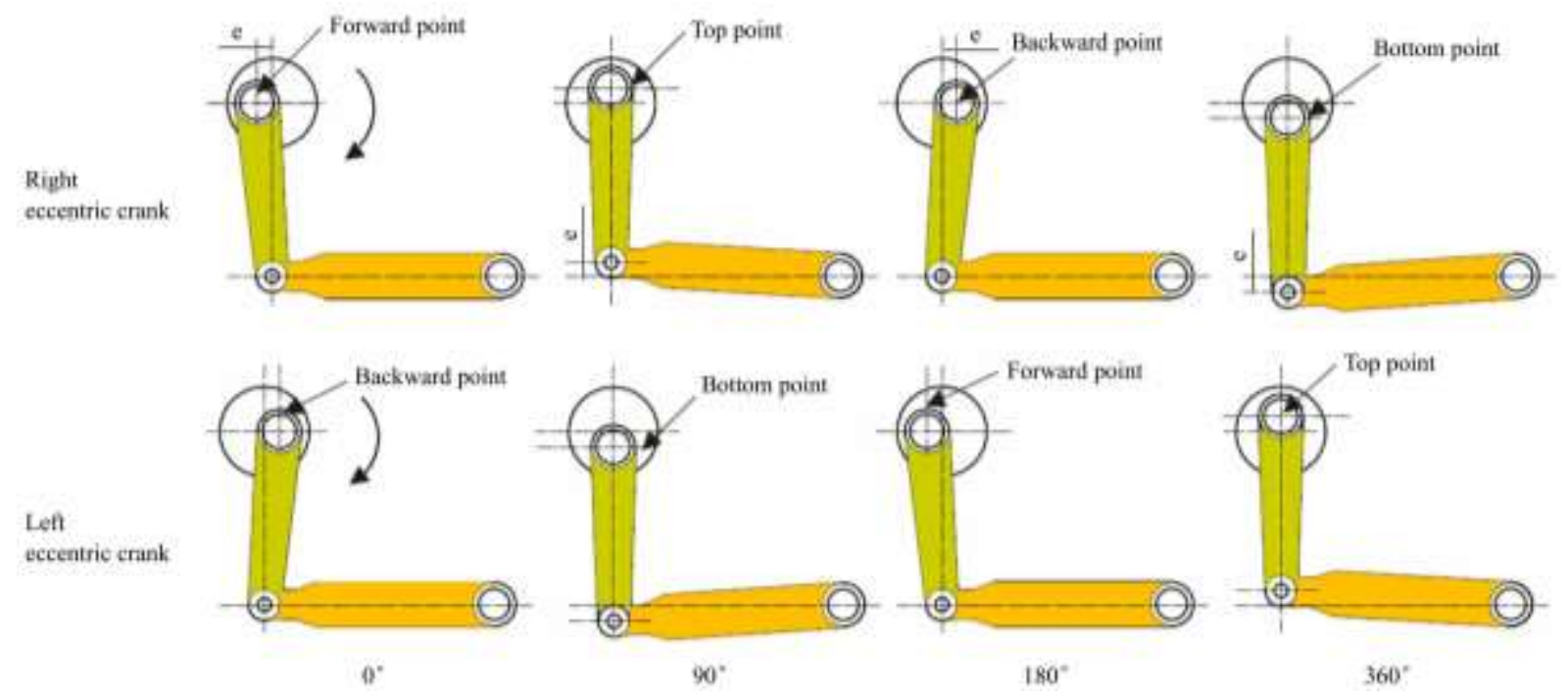

Figure 3 Dynamic position of the two eccentric cranks placed at a phase difference of $180^{\circ}$ when rotating clockwise $0^{\circ}-360^{\circ}$

Figure 4 illustrates how to create the V-shape arrangement for shanks. The two reciprocating motion units are placed symmetrically in the horizontal direction. Every two shanks are installed on the right or left reciprocating motion unit in the diagonal direction with the horizontal distance of $600 \mathrm{~mm}$. The two shanks attached in the inner side of each reciprocating motion unit will be on the front row with the horizontal distance of $600 \mathrm{~mm}$. And the other two shanks placed in the outer side of each reciprocating motion unit will be on the rear row with distance of $1800 \mathrm{~mm}$. Consequently the final shape of shanks on the frame will be as V-shape.

Under these arrangements, the front shank will move down and penetrate the unplowed soil only while the rear shank finish soil cutting and start moving up. This means that only one shanks of each reciprocating unit penetrates the hard soil at once, which reduce the total soil resistance on the subsoiler.

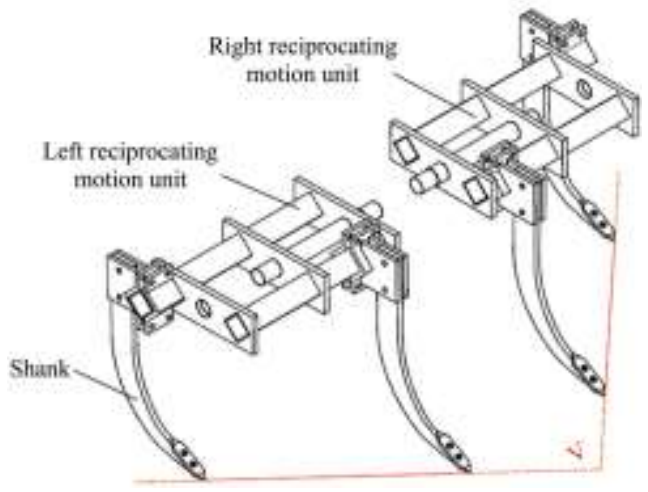

Figure 4 Shanks arranged at V-shape

\section{MATLAB simulation}

Yow and Smith ${ }^{[16]}$ analyzed the trajectory of one dimensional sinusoidal vibratory tillage and found that the tillage force reduction was determined by the vibratory frequency and forward speed of the implement. The tillage force reduction was achieved when the ratio of peak vibration velocity to the forward speed of the tool was greater than 1. To obtain decreased draft force, the effect of forward speed and vibratory frequency on the shanks trajectory should be investigated. In this study, the trajectory equations of shanks was obtained first and three forward speeds $(2 \mathrm{~km} / \mathrm{h}, 3 \mathrm{~km} / \mathrm{h}$, and $4 \mathrm{~km} / \mathrm{h}$ ) combining with three frequencies (9 Hz, $12 \mathrm{~Hz}$, and $15 \mathrm{~Hz}$ ) were simulated in the MATLAB software (MATLAB R2017).

\subsection{Trajectory analysis of shanks}

The trajectory of shanks arranged at the V-shape was analyzed. A simplified planar model was built. As shown in Figure 5, $A B C D$ is the original position of the rear and front tines, $A^{\prime} B^{\prime} C^{\prime} D^{\prime}$ is the position after the vibration by angle $\beta$ and $O$ is the origin. $\alpha$ is the angles of line $O D$ and line $O A$ to $y$-axis. The tractor forward direction is opposite to the $x$-axis.

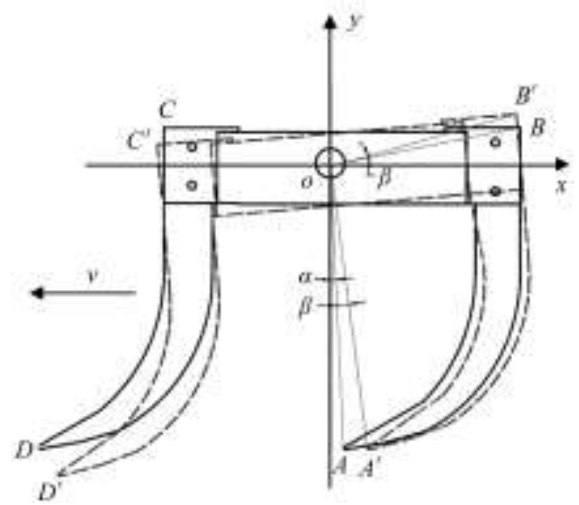

Figure 5 Trajectory analysis of shanks

Point $B$ has a simple harmonic motion in the direction of $y$-axis with the amplitude of $a$ and period of $1 / f$, where $f$ is vibratory frequency that is determined by the transmission ratio of gear box, $a$ is determined by the design parameters. The trajectory equations of $B^{\prime}$ is as follow:

$$
\left\{\begin{array}{l}
x_{B^{\prime}}=-v t+l_{O B} \cos 2 \pi f t \\
y_{B^{\prime}}=a \sin 2 \pi f t
\end{array}\right.
$$

The trajectory equation of the rear tine $A$ can be calculated as bellow:

$$
\left\{\begin{array}{l}
x_{A^{\prime}}=-v t+l_{O A} \sin (\alpha+\beta) \\
y_{A^{\prime}}=-l_{O A} \cos (\alpha+\beta)
\end{array}\right.
$$

where, $l_{O A}$ is the distance between point $A$ and point $O, \mathrm{~mm} ; v$ is tractor forward speed, $\mathrm{km} / \mathrm{h} ; l_{O B}$ is the distance between point $O$ and point $B, \mathrm{~mm}$.

Because the two points $B$ and $A$ are one unit that means they have same circular rotation therefore the vibratory angle $\beta$ will be as bellow:

$$
\beta=\arcsin \frac{y_{B^{\prime}}}{l_{O B^{\prime}}}
$$

Incorporating the above Equations (1)-(3), the trajectory 
equation of tine $A$ can be as follow:

$$
\left\{\begin{array}{l}
x_{A^{\prime}}=-v t+l_{O A} \sin \left(\alpha+\arcsin \frac{a \sin 2 \pi f t}{l_{O B}}\right) \\
y_{A^{\prime}}=-l_{O A} \cos \left(\alpha+\arcsin \frac{a \sin 2 \pi f t}{l_{O B}}\right)
\end{array}\right.
$$

\subsection{Simulation results}

The trajectory equations of tine $A$ was input to the MATLAB software and the vibrating paths of the shanks were simulated as shown in Figure 6. A study by Niyamapa et al. ${ }^{[20]}$ showed that
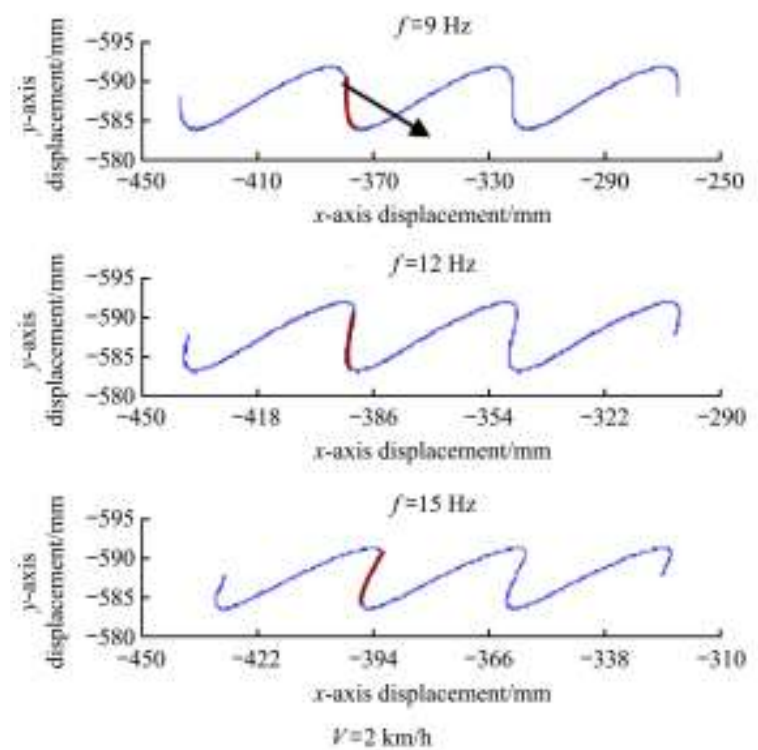

when the ratio of peak vibration velocity to the forward speed was less than 1 , the cutting blade always moved forward relative to the soil. Increasing the velocity ratio to 1 meant cutting blade tip velocity decreased to zero once per cycle, however, still moving forward into uncut soil. When the velocity ratio became greater than 1 , the cutting blade moved backward relative to the soil during part of each cycle thus to reduce the draft force efficiently. Butson $^{[21]}$ stated that when the velocity ratio was greater than 1 , the process of cutting down and lifting up the soil was conducted separately and the shank had a backward vertical movement.
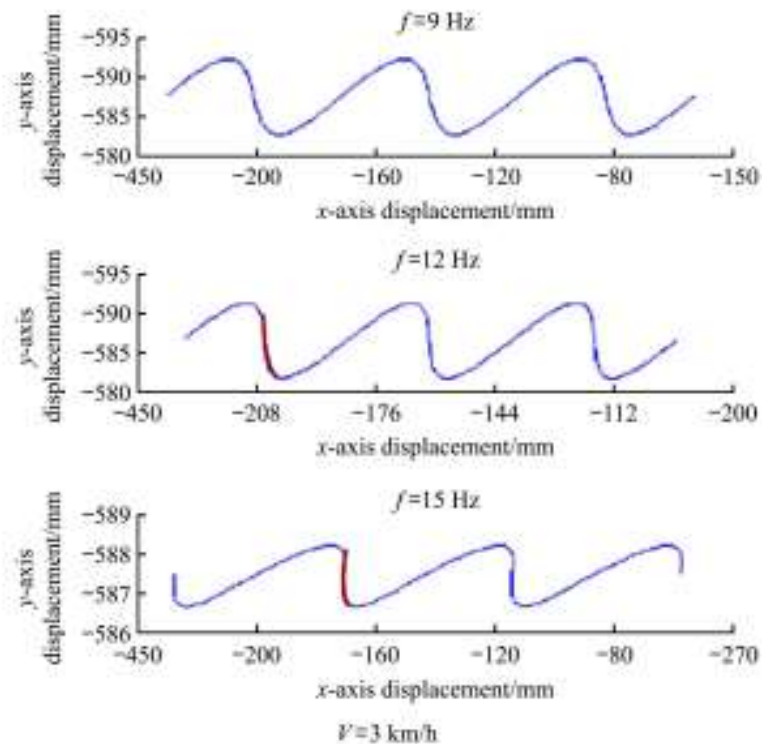

$f=9 \mathrm{~Hz}$
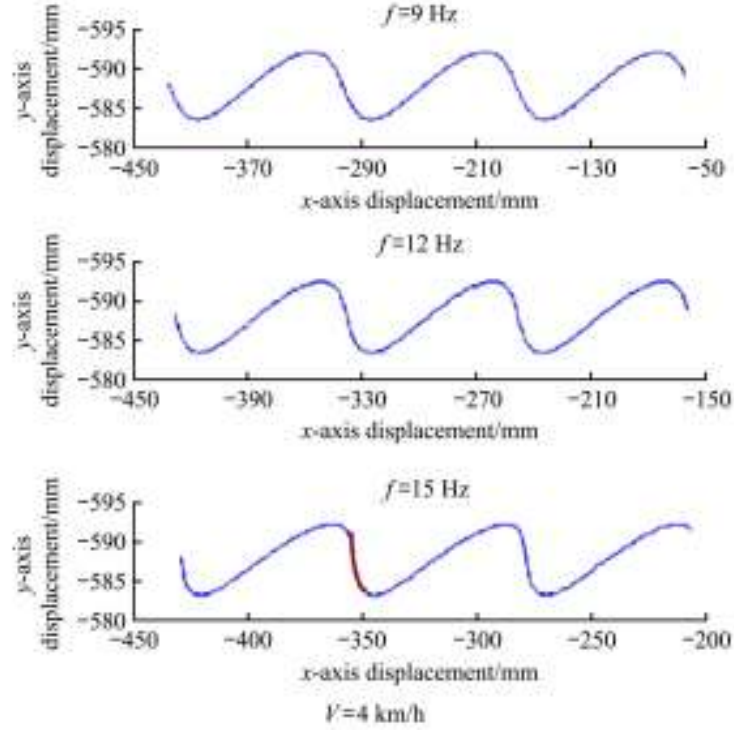

Figure 6 MATLAB simulation of shanks trajectory at different forward speeds with different vibrating frequencies

Figure 6 shows the simulation results of all treatments. For the forward speed of $2 \mathrm{~km} / \mathrm{h}$ with vibrating frequency of $9 \mathrm{~Hz}$, $12 \mathrm{~Hz}, 15 \mathrm{~Hz}$ and $3 \mathrm{~km} / \mathrm{h}$ with vibrating frequency of $12 \mathrm{~Hz}, 15 \mathrm{~Hz}$, and $4 \mathrm{~km} / \mathrm{h}$ with vibrating frequency of $15 \mathrm{~Hz}$, the backward vertical movement was observed. For this condition, the soil resistance could be reduced effectively. It is also illustrated that the high forward speed needed high vibrating frequency to guarantee the decrease in draft force. However, high vibration frequency requires more energy. Yow and $S_{m i t h}{ }^{[16]}$ stated the draft force reduction of a vibrating subsoiler was up to $30 \%$ whereas the power consumption increased by $50 \%$ at the velocity ratio of 2. Considering the power requirement, the forward speed of $2-3 \mathrm{~km} / \mathrm{h}$ with vibrating frequency of $12 \mathrm{~Hz}$ is recommended for this vibrating subsoiler.

\section{Field experiment}

The field experiment was carried out to evaluate the field performance of the staggered vibrating subsoiler by comparing the staggered vibrating (SV) to rigid (NV) working mode of shanks, as shown in Figure 7.

The draft force reduction is an important index to evaluate the working performance for the vibrating subsoiler. The small and stable draft force is expected for tractor to obtain stable load and reduce the slippage. But the forced vibrating subsoiler requires 
the extra power consumption of the tractor. Therefore, in this paper, besides the draft force and wheel slippage, the power requirement is also selected as evaluation indexes.

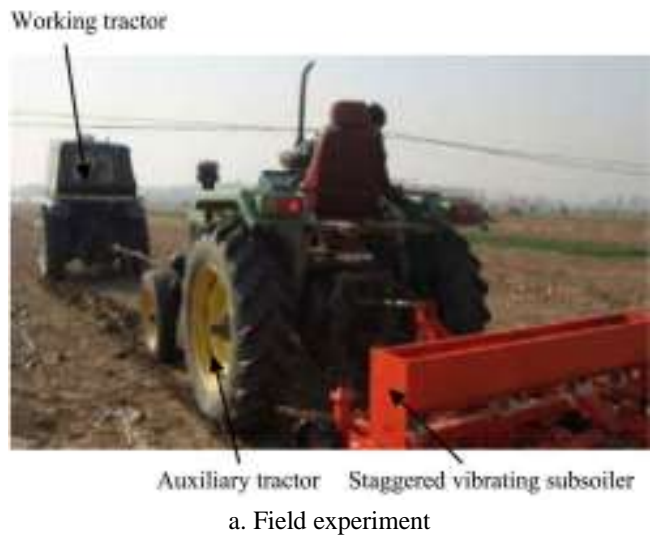

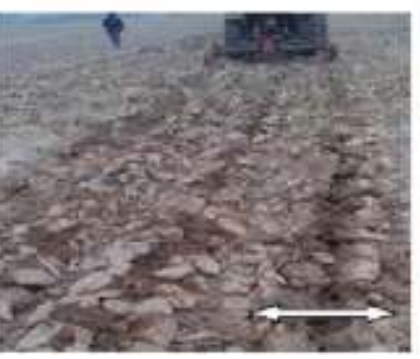

b. Operation by SV



c. Operation by NV
Figure 7 Field experiment and top soil disturbance respective with SV and NV

\subsection{Test condition}

The experiment was carried out at Gu'an, Hebei Province $\left(116^{\circ} 17^{\prime} \mathrm{E}, 39^{\circ} 19^{\prime} \mathrm{N}\right)$, where the soil type is silt clay. The site was a maize field after harvesting with the stubble remained in the field (Figure 7).

Three different forward speeds $(2.2 \mathrm{~km} / \mathrm{h}, 2.6 \mathrm{~km} / \mathrm{h}$ and $3.1 \mathrm{~km} / \mathrm{h}$ ) with vibrating frequency of $12 \mathrm{~Hz}$ were selected for the experiments. Where, the staggered vibrating shank (SV) was obtained through operating the implement with the tractor PTO and the rigid shank (NV) was obtained by turning off the PTO of the tractor. Each treatment was arranged in split-plot design with three replicates.

\subsection{Evaluation indexes}

\subsubsection{Draft force}

Two tractors are used for the measurement of draft force, one auxiliary (the rear) tractor for suspending the subsoiler and one working (the front) tractor for pulling the auxiliary tractor (Figure 7a). The power of this measurement system is supplied by the working tractor. A digital dynamometer with a capacity of $1000 \mathrm{kN}$ is linked to the front of the working tractor and the auxiliary tractor. Meanwhile the dynamometer is connected to a data acquisition system constituted of the data logger which is connected to a portable computer.

Measurement of draft force is done as follows process. Fist, the subsoiler is put in operation position (loaded) and the auxiliary tractor is pulled to record the force $F_{1}$. Then the subsoiler is lifted up from the soil (unloaded) and the auxiliary tractor is pulled to record the force $F_{2}$.

The draft force for subsoil tillage $(F)$ is calculated as follows:

$$
F=F_{1}-F_{2}
$$

\subsubsection{Power requirement}

The power requirement of the vibrating subsoiler should be the summary of draft power (Dtpr) for pulling the subsoiler and the
PTO power (PTOpr) for driving the vibrating mechanism. The draft power and the PTO power are calculated as follows:

$$
\begin{gathered}
\text { Dtpr }=(F \cdot v) / 3.6 \\
\text { PTOpr }=\frac{T \cdot \omega}{9550}
\end{gathered}
$$

where, $v$ is the forward speed, $\mathrm{km} / \mathrm{h} ; T$ is the PTO torque, $\mathrm{N} \cdot \mathrm{m} ; w$ is the PTO rotate speed, $\mathrm{r} / \mathrm{min}$. The torque and the rotate speed are measured simultaneously by a torsiometer that is located between the tractor PTO shaft and the input shaft of the gear box of the subsoiler.

The total power requirement (Talpr) of the subsoiler is calculated by the following equation:

\subsubsection{Wheel slippage}

$$
\text { Talpr }=D t p r+P T O p r
$$

Wheel slippage is the travel reduction of the implement during operation in the field and usually expressed in percentage ${ }^{[22]}$. The wheel slippage is determined as follows. Fist, the rear wheel of the tractor is marked by a piece of chalk at a position tangent to ground surface. Second, a distance $\left(d_{1}\right)$ covered by five revolutions of the wheel is measured when the tractor is unloaded with subsoiler. Finally, another distance $\left(d_{2}\right)$ covered by the same number of revolutions is measured when the tractor is loaded with the subsoiler.

The wheel slippage is calculated as follows:

$$
S=\left(\frac{d_{1}-d_{2}}{d_{2}}\right) \times 100 \%
$$

\subsection{Statistics analysis}

Analysis of variance (ANOVA) was conducted using statistical software (IBM SPASS Statistics 21, IBM, USA). Duncan's multiple range tests was used to identify the significant different among all

\begin{tabular}{|c|c|c|c|c|c|c|}
\hline & \multicolumn{2}{|c|}{ Draft force } & \multicolumn{2}{|c|}{ Power requirement } & \multicolumn{2}{|c|}{ Wheel slippage } \\
\hline & $p$ value & significance & $p$ value & significance & $p$ value & significance \\
\hline $\begin{array}{l}\text { Forward } \\
\text { speed }\end{array}$ & 0.0287 & $*$ & 0.0004 & $* *$ & 0.0394 & $*$ \\
\hline $\begin{array}{l}\text { Operation } \\
\text { mode } \\
\text { (NV or } \mathrm{SV})\end{array}$ & 0.0383 & $*$ & 0.0760 & $\mathrm{~ns}$ & 0.0235 & $*$ \\
\hline
\end{tabular}
the treatments. The level of probability value was set at 0.05 for all comparisons. The result of ANOVA is shown in Table 2.

Table 2 ANOVA of forward speed and operation mode on draft force, power requirement and wheel slippage

(NV or SV)

Note: ${ }^{* *}$ and $*$ represent significant; ${ }^{* *}$ represents $p<0.01, *$ represents $p<0.05$; ns represents no significant.

\subsection{Results and discussion.}

\subsubsection{Draft force}

The operation mode (SV and NV) had significant effect on the draft force $(p=0.0383)$ (Table 2). The SV operation mode acquired low draft force comparing to NV operation mode at three forward speeds (Figure 8). The average draft force for SV was lower than that of NV by $16.97 \%, 12.12 \%$ and $9.02 \%$ respectively at forward speed of $2.2 \mathrm{~km} / \mathrm{h}, 2.6 \mathrm{~km} / \mathrm{h}$ and $3.1 \mathrm{~km} / \mathrm{h}$ (Table 3 ). That is better than the research for the 1SZ-460 vibratory subsoiler acquiring decrease in draft force by $9.09 \%$ being done at the same place with similar condition ${ }^{[23]}$. The considerable decrease in draft force can help the tractor overcome the overloading conditions when works with hard soil resistance. The findings of this study are consistent with those of Yow and Smith ${ }^{[16]}$ and Slattery and Gholamhossein et al. ${ }^{[2]}$ who reported that vibratory subsoiler was one technique to reduce the draft force. 

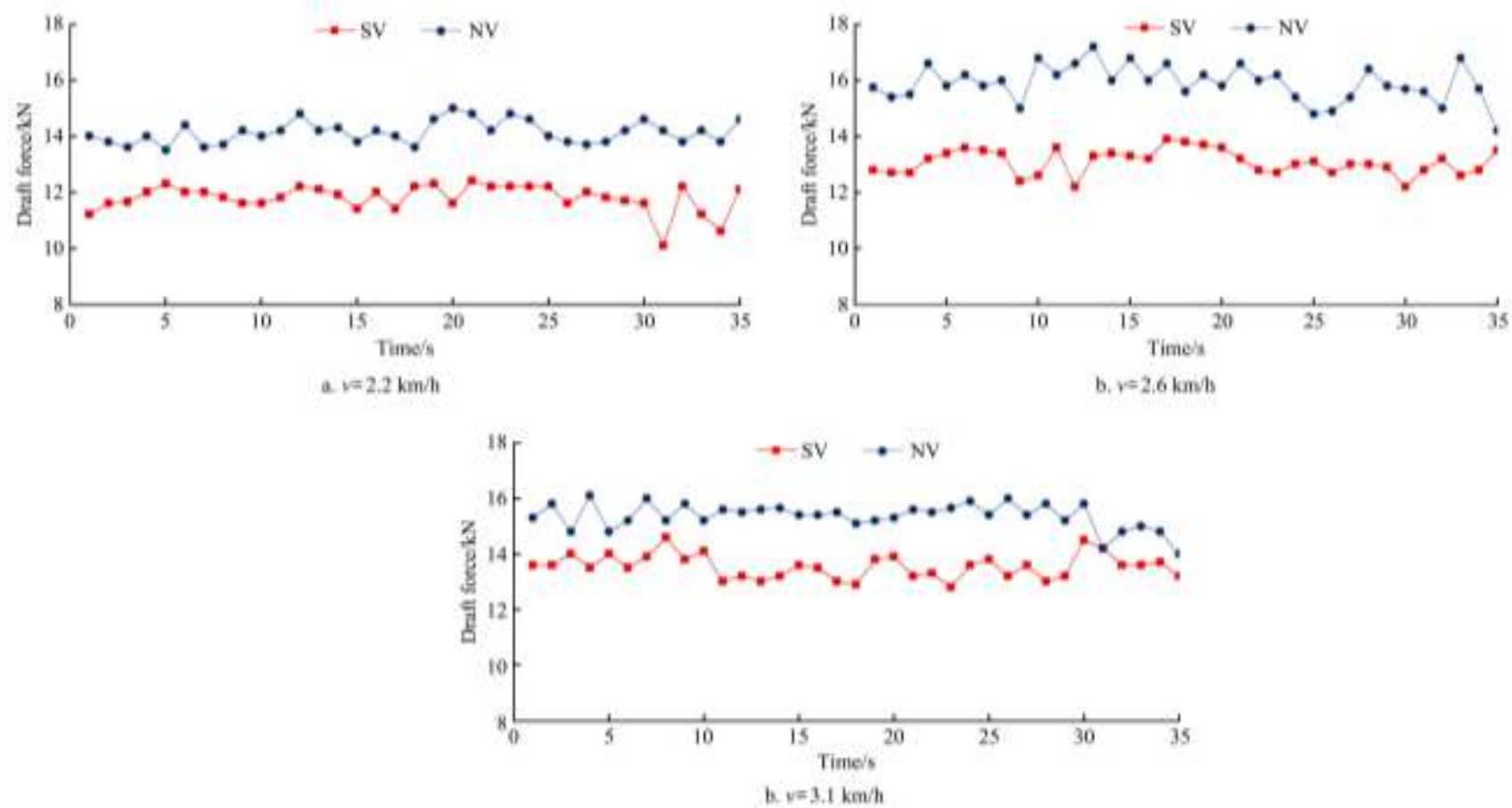

Figure 8 Dynamic draft force acquiring by the digital dynamometer at different forward speeds

Table 3 Mean values of draft force, power requirement and wheel slippage at different forward speeds

\begin{tabular}{|c|c|c|c|c|c|c|c|c|c|}
\hline \multirow{2}{*}{ Speed $/ \mathrm{km} \cdot \mathrm{h}^{-1}$} & \multicolumn{3}{|c|}{ Draft force } & \multicolumn{3}{|c|}{ Power requirement } & \multicolumn{3}{|c|}{ Wheel slippage } \\
\hline & $\mathrm{SV} / \mathrm{kN}$ & $\mathrm{NV} / \mathrm{kN}$ & Decrease ratio/\% & $\mathrm{SV} / \mathrm{kW}$ & $\mathrm{NV} / \mathrm{kW}$ & Increase ratio/\% & $\mathrm{SV} / \%$ & $\mathrm{NV} / \%$ & Decrease ratio/\% \\
\hline 2.2 & 11.59 & 13.65 & 16.97 & 8.91 & 8.16 & 9.27 & 17.21 & 19.67 & 12.47 \\
\hline 2.6 & 12.78 & 14.54 & 12.12 & 11.23 & 10.79 & 4.89 & 14.48 & 17.65 & 17.96 \\
\hline 3.1 & 13.99 & 15.37 & 9.02 & 11.55 & 11.07 & 5.96 & 13.33 & 17.05 & 21.79 \\
\hline
\end{tabular}

The draft force was significantly affected by forward speed $(p=0.0287)$ (Table 2). It presented an increasing trend in draft force over speed for all treatments (Table 3). The increase in draft force may be due to the fact that the increasing forward speed will accelerate the movement of soil particles rapidly, thus increasing the frictional forces on tines. On the other hand, the increase in draft force with the increase of speed may be due to the increase in rate of soil shear ${ }^{[25]}$. This result is in agreement with Sun et al. ${ }^{[19]}$ who found that the draft force increased with increase in forward speed. McLaughlin and Campbell ${ }^{[26]}$ concluded that the forward speed was a significant determinant of draft force that increased in a linear or quadratic with the forward speed.

\subsubsection{Power requirement}

The power requirement was significantly affected by the forward speed but not significant by the operation mode (Table 2). The results showed an increasing trend in power requirement over speeds for all treatments. That was resulted from the increase of draft force. The power of VS operation mode was slightly greater than that of NV by $9.27 \%$ for speed of $2.2 \mathrm{~km} / \mathrm{h}, 4.89 \%$ for speed of $2.6 \mathrm{~km} / \mathrm{h}$ and $5.96 \%$ for speed of $3.1 \mathrm{~km} / \mathrm{h}$ (Table 3 ). But the statistically no significant difference $(p=0.0760)$ was observed in power requirements between two operation mode (VS and NS) for the three different forward speeds.

4.4.3 Wheel slippage

ANOVA analysis illustrated that both forward speed $(p=0.0394)$ and operation mode $(p=0.0235)$ had significant effect on the wheel slippage (Table 2). The average wheel slippage for SV was found to be significantly lower than that of NS at different forward speed. The wheel slippage of VS operation mode was lower than that of NV by $12.47 \%$ for speed of $2.2 \mathrm{~km} / \mathrm{h}, 17.96 \%$ for speed of $2.6 \mathrm{~km} / \mathrm{h}$ and $21.79 \%$ for speed of $3.1 \mathrm{~km} / \mathrm{h}$ (Table 3 ). Generally, the tractor is easy to skid at overloading conditions ${ }^{[27,28]}$. So, this means that the decrease in draft force of VS is favor to avoid the overloading soil resistance compared with the NV. This finding is in agreement with Bandalan et al. ${ }^{[9]}$ and Busscher et al. ${ }^{[29}$ who stated that the increase in machine draft force was accompanied by increase in wheel slippage.

The wheel slippage was observed to decrease over speeds for all treatments (Table 3). The wheel slippage decreased from $17.21 \%$ to $13.33 \%$ and from $19.67 \%$ to $17.05 \%$ as the forward speed increased from $2.2 \mathrm{~km} / \mathrm{h}$ to $3.1 \mathrm{~km} / \mathrm{h}$ for $\mathrm{VS}$ and $\mathrm{NV}$ respectively (Table 3 ). The decrease in slippage at higher speeds may be due to the larger momentum of the implement. This result agrees with Abdalla et al. ${ }^{[30]}$ who observed that the increase in speed was accompanied by decrease in slippage.

\section{Conclusions}

A staggered vibrating subsoiler characterized by a new staggered vibrating mechanism and V-shape shanks arrangement was developed. Field experiment was conducted to evaluate the working performance by the draft force, power requirement and wheel slippage. The conclusions of the research can be drawn as follows:

(1) The trajectory of shanks was simulated by using the MATLAB software. Results indicate that the optimum forward speed and vibration frequency for this subsoiler were $2-3 \mathrm{~km} / \mathrm{h}$ and $12 \mathrm{~Hz}$, respectively. 
(2) Field experiment testified that the staggered vibrating subsoiler demonstrated good working performance by reducing more draft force comparing with the research for the 1SZ-460 vibratory subsoiler being done under the similar condition. The draft forces were decreased by $16.97 \%, 12.12 \%$ and $9.02 \%$ at forward speeds of $2.2 \mathrm{~km} / \mathrm{h}, 2.6 \mathrm{~km} / \mathrm{h}$ and $3.1 \mathrm{~km} / \mathrm{h}$, respectively.

(3) The wheel slippage of the vibrating subsoiler was significantly decreased by $12.47 \%, 17.96 \%$ and $21.79 \%$ at three forward speeds, respectively. Therefore, it is recommended to be applied in subsoil tillage process for developing countries.

\section{Acknowledgements}

This work was supported by China's Ministry of Agriculture, Agricultural Public Welfare Industry Research (201503117), China's Ministry of Agriculture, Agricultural Public Welfare Industry Research (201503116-16), and the Soil-Machine-Plant Key Laboratory of the Ministry of Agriculture of China.

\section{[References]}

[1] Vakali C, Zaller J G, Köpke U. Reduced tillage effects on soil properties and growth of cereals and associated weeds under organic farming. Soil and Tillage Research, 2011; 111(2): 133-141.

[2] Evans S D, Lindstrom M J, Voorhees W B, Moncrief J F, Nelson G A. Effect of subsoiling and subsequent tillage on soil bulk density, soil moisture, and corn yield. Soil and Tillage Research, 1996; 38(1): 35-46.

[3] Ansorge D, Godwin R J. The effects of tyres and a rubber track at high axle loads on soil compaction: part 2. Multi axle machine studies. Biosystems Engineering, 2008; 99(3): 338-347.

[4] Arvidsson J, Trautner A, van der Akker J J H, Schjonning P. Subsoil compaction caused by heavy sugarbeet harvesters in southern Sweden: II. Soil displacement during wheeling and model computations of compaction. Soil and Tillage Research, 2001; 60 (1-2): 79-89.

[5] Schjonning P, Rasmussen K J. Soil strength and soil pore characteristics for direct drilled and ploughed soils. Soil and Tillage Research, 2000; 57(1-2): 69-82.

[6] Hemmata A, Adamchukb V I. Sensor systems for measuring soil compaction: Review and analysis. Computers and electronics in agriculture, 2008; 63(2): 89-103.

[7] Jorajuria D, Draghi L, Aragon A. The effect of vehicle weight on the distribution of compaction with depth and the yield of Lolium/Trijiolium grassland. Soil and Tillage Research, 1997; 41(S1-2): 1-12

[8] Sivarajan S, Maharlooei M, Bajwa S G, Nowatzki J. Impact of soil compaction due to wheel traffic on corn and soybean growth, development and yield. Soil and Tillage Research, 2018; 175: 234-243.

[9] Bandalan E P, Salokhe V M, Gupta C P. Performance of an oscillating subsoiler in breaking a hardpan. Journal of Terramechanics, 1999; 36(2): $117-125$

[10] Sulatisky M T, Ukrainetz P R. Draft reduction by vibratory soil cutting. Transactions of the Canadian Society for Mechanical Engineers, 1972; 1(4) 175-181

[11] Qin H L, Gao W S, Ma Y C, Ma L, Yin C M, Chen Z, et al. Effects of subsoiling on soil moisture under no tillage for two years. Agricultural Sciences in China, 2008; 7(1): 88-95. (in Chinese)
[12] Busscher W J, Bauer P J. Soil strength, cotton root growth, and lint yield in a southeastern USA coastal loam sand. Soil and Tillage Research, 2003; 74(2): 151-159.

[13] Kamprath E J, Cassel D K, Gross H D, Dibb D W. Tillage effects on biomass production and moisture utilization by soybean on coastal plain soils. Agronomy Journal, 1979; 71(6): 1001-1005.

[14] Mohanty M, Bandyopadhyay K K, Painuli D K, Ghosh P K, Misra A K, Hati K M. Water transmission characteristics of a vertisol and water use efficiency of rainfed soybean under subsoiling. Soil and tillage Research, 2007; 93(2): 420-428.

[15] Zhang X R, Wang C, Chen Z S, Zeng Z W. Design and experiment of a bionic vibratory subsoiler for banana fields in southern China. Int J Agric \& Biol Eng, 2016; 9(7): 75-83.

[16] Yow J, Smith J L. Sinusoidal vibratory tillage. Journal of Terramechanics, 1976; 13(4): 211-226.

[17] Guillen-Sánchez J, Campos-Magaña S G, Sánchez-López C, González-Brambila O M, Ramírez-Fuentes G. Experimental apparatus to determine the power applied in vibrating vertical tillage. AgricEngInt: CIGR Journal, 2017; 19(2): 68-75.

[18] Shahgoli G, Saunders C, Desbiolles J, Fielke J. The effect of oscillation angle on the performance of oscillatory tillage. Soil and Tillage Research, 2009; 104(1): 97-105.

[19] Sun Y P, Dong X Q, Song J N, Liu C L, Wang J C, Zhang C. Parameter optimization of vibration subsoiler test bed for reducing resistance and vibration. Transactions of the CSAE, 2016; 32(24): 43-49. (in Chinese)

[20] Niyamapa T, Salokhe V M. Force and pressure distribution under vibratory tillage tool. Journal of Terramechanics, 2000; 37(3): 139-150.

[21] Butson M J, Rackham D H. Vibratory soil cutting: II. An improved mathematical model. Journal of Agricultural Engineering Research, 1981 26(5): 419-439.

[22] Cay A, Kocabiyik H, May S. Development of an electro-mechanic control system for seed-metering unit of single seed corn planters Part II: Field performance. Computers and Electronics in Agriculture, 2018; 145: 11-17.

[23] Li X, Zhang D X, Wang W X, Cui T, Tang M J. Performance parameter optimization and experiment of forced-vibration subsoile. Transactions of the CSAE, 2015; 31(21): 17-24. (in Chinese)

[24] Gholamhossein S, John F, Jacky D, Chris S. Optimising oscillation frequency in oscillatory tillage. Soil and Tillage Research, 2010; 106(2): 202-210.

[25] Wheeler P N, Godwin R J. Soil dynamics of single and multiple tines at speeds up to $20 \mathrm{~km} / \mathrm{h}$. Journal of Agricultural Engineering, 1996; 63(3): 243-250.

[26] McLaughlin N B, Campbell A J. Draft-speed-depth relationships for four liquid manure injectors in a fine sandy loam soil. Canadian Biosystems Engineering, 2004; 46: 2(1-5).

[27] Abo-Elnor M, Hamilton R, Boyle J T. Simulation of soil-blade interaction for sandy soil using advanced $3 \mathrm{D}$ finite element analysis. Soil and Tillage Research, 2004; 75(1): 61-73.

[28] TrapP A D, Abrahams M, Reece A R. The performance of longitudinally vibrating earth cutters. J. Agric. Eng. Res, 1974; 19(4): 371-390.

[29] Busscher W J, Bauer P J, Frederick J R. Deep tillage management for high strength southeastern USA Coastal Plain soils. Soil and Tillage Research, 2006; 85(1-2): 178-185.

[30] Abdalla N O, Li X, Zhang D X. Effects of tilt angle of disk plough on some soil physical properties, work rate and wheel slippage under light clay soil. Int J Agric \& Biol Eng, 2011; 4(2): 29-35. 